\title{
EL PAPEL DEL TRIBUNAL SUPREMO Y DEL TRIBUNAL CONSTITUCIONAL EN LA PROTECCIÓN DE LOS DERECHOS Y LIBERTADES FUNDAMENTALES DENTRO DEL PROCESO PENAL
}

\author{
Jaime VEgAS TORRES \\ Catedrático de Derecho Procesal \\ Universidad Rey Juan Carlos \\ jaime.vegas@urjc.es
}

\begin{abstract}
RESUMEN
En este trabajo el autor analiza cuáles son los cauces previstos actualmente en el ordenamiento español para la protección de los derechos fundamentales en el proceso penal, baciendo un análisis más detallado del papel ejercido por el Tribunal Constitucional, sobre todo desde la reforma de 2007. Examina además en detalle la importancia de esta doctrina para la protección de derechos tan relevantes como la presunción de inocencia, el juez imparcial o el derecho a un proceso con todas las garantías, así como para el desarrollo de ciertas diligencias restrictivas de derechos fundamentales como la intervención de las comunicaciones.
\end{abstract}

Palabras clave: Tribunal Constitucional, Tribunal Supremo, proceso penal, derechos fundamentales, amparo.

\section{ABSTRACT}

With this piece of work the writer looks into the currently existing channels in Spanish legal system for the protection of basic rights in Penal Law, with a thorough analysis of the role the Constitutional Court has had, particularly since 2007 amendments. It also looks deeply into the importance of such doctrine for the protection of such relevant rights as Presumption of Innocence, the right to an impartial or fully guaranteed judgement, together with the development of certain diligence which limit basic rights such as communication intervention.

Keywords: Constitutional Court, Supreme Court, Penal Procedure, Fundamental Rights, Protection.

\section{ZUSAMMENFASSUNG}

In der vorliegenden Arbeit untersucht der Autor innerbalb der spanischen Rechtsordnung die heutigen vorgesehenen Verfabren, die den Schutz der Grundrechte im Strafverfabren gewährleisten. Hierzu wurde eingehend die Rolle des Spanischen 
Verfassungsgerichts untersucht, vor allem seit seiner Reform im Jabr 2007. Ferner untersucht die vorliegende Arbeit detailliert die Bedeutung dieser Lehrauffassung zum Schutz wichtiger Rechte, wie z.B. dem Recht der Unschuldsvermutung, der Unparteilichkeit der Richter und der Garantie der Rechtstaatlichkeit, angesichts der Ausübung von restriktiven Maßnabmen gegenüber den Menschenrechten, wie z.B. der Eingriff in die Freiheit der Kommunikationsnetzwerke.

Schlüsselwörter: Verfassungsgericht, Oberster Gerichtshof, Strafsrecht, Grundrechte, Schutz.

En la Constitución Española de 1978, los derechos fundamentales que interesan cuando hablamos de la justicia penal forman parte del núcleo de derechos más intensamente protegidos, que son, junto al principio de igualdad del art. 14, los reconocidos en la sección primera del capítulo segundo del título primero, arts. 15 a 29.

En estos preceptos encontramos el derecho a la vida y a la integridad física y moral; la prohibición de la tortura y de las penas o tratos inhumanos y degradantes; la abolición de la pena de muerte; el derecho a no declarar sobre la ideología, religión o creencias; el derecho a la libertad personal, con los límites temporales y requisitos de la detención preventiva; el habeas corpus; la inviolabilidad del domicilio; el secreto de las comunicaciones; la protección frente al uso de la informática, y, muy especialmente, los derechos de los arts. 24 y 25 sobre garantías del proceso penal, principio de legalidad penal y finalidad de las penas.

La Constitución quiso establecer una tutela jurisdiccional particularmente intensa de estos derechos fundamentales. Por ello, el art. 53.2 dispone que «cualquier ciudadano podrá recabar la tutela de las libertades y derechos reconocidos en el art. 14 y la sección primera del capítulo segundo ante los tribunales ordinarios por un procedimiento basado en los principios de preferencia y sumariedad y, en su caso, a través del recurso de amparo ante el Tribunal Constitucional».

Este precepto constitucional contempla, por tanto, dos vías para la tutela jurisdiccional de los derechos fundamentales: ante los tribunales de la jurisdicción ordinaria, a través de un procedimiento preferente y sumario, y ante el Tribunal Constitucional, mediante el recurso de amparo constitucional.

La primera de estas dos vías (el procedimiento preferente y sumario ante los tribunales ordinarios) solamente tiene sentido cuando se trata de la tutela de derechos fundamentales frente a lesiones producidas fuera del proceso; se contemplan situaciones en que, ante una lesión de derechos 
fundamentales cometida por sujetos distintos de los tribunales y fuera de un contexto procesal, quien ha padecido la lesión acude al tribunal formulando una pretensión de tutela del derecho fundamental lesionado. Lo que se deriva del precepto constitucional es que, para este tipo de pretensiones, las leyes procesales han de contemplar cauces procesales que aseguren la preferencia de estos asuntos sobre otros, así como una tramitación más ágil.

A esta exigencia constitucional responden determinadas especialidades previstas en las leyes procesales para procesos que tienen por objeto pretensiones de tutela de derechos fundamentales. Así, para la tutela de estos derechos por los tribunales civiles la Ley de Enjuiciamiento Civil dispone que el proceso siga los trámites del juicio ordinario, pero ordenando que la tramitación de estos juicios tenga carácter preferente, así como que intervenga en ellos como parte el Ministerio Fiscal (art. 249.1.2. ${ }^{\circ}$ ); se prevé también que en los procesos sobre tutela judicial civil de los derechos fundamentales no procesales sea siempre posible el recurso de casación, con independencia de la cuantía de la reclamación y de que el recurso presente o no interés casacional (art. 477.2.1. ${ }^{\circ}$ ).

Para la tutela de los derechos fundamentales por los tribunales del orden contencioso-administrativo frente a actuaciones de las Administraciones Públicas lesivas de estos derechos, los arts. 114 a 122 bis de la Ley Reguladora de la Jurisdicción Contencioso-Administrativa regulan un procedimiento especial caracterizado por la preferencia en la tramitación y por un acortamiento de los plazos del recurso contencioso-administrativo.

En la jurisdicción social también existe un procedimiento especial, previsto en los arts. 177 a 184 de la Ley Reguladora de la Jurisdicción Social, para los casos en que se presentan ante los tribunales laborales demandas sobre lesiones de derechos fundamentales y libertades públicas producidas en el ámbito de las relaciones laborales.

En el orden penal no existe, sin embargo, ningún cauce procesal especial para pretensiones basadas en lesiones de derechos fundamentales producidas fuera de un proceso. ¿Significa esto que en el orden penal no se cumplen las exigencias constitucionales en materia de tutela de los derechos fundamentales, o que la tutela de estos derechos ante los tribunales penales sea de menor intensidad que ante los demás órdenes jurisdiccionales? La respuesta, por supuesto, es negativa.

En el orden penal, el proceso preferente y sumario previsto en el art. 53.2 de la Constitución solamente tendría sentido para las causas penales por delitos que constituyan ataques a los derechos fundamenta- 
les. Lo que estaría en juego, en definitiva, sería la tutela por los tribunales penales de los derechos fundamentales de la víctima del delito lesionados por el delincuente. Desde esta perspectiva, hay razones de peso que pueden justificar que no se haya establecido un procedimiento preferente y sumario para esas causas penales. Por una parte, es cuando menos discutible que forme parte del contenido de los derechos fundamentales que se imponga la pena prevista en el Código Penal a quien cometa un delito que lesione esos derechos. El ius puniendi es del Estado y no de los titulares de los bienes jurídicos protegidos por la norma penal, y esto es así incluso cuando el bien jurídico protegido es o incluye el contenido de un derecho fundamental.

También existen razones prácticas que abonan la inconveniencia de establecer tramitaciones especiales para causas penales por delitos que lesionen derechos fundamentales: por una parte, si bien se mira, la mayoría de los delitos lesiona algún derecho fundamental de la víctima, lo que supondría que las especialidades tendrían que aplicarse en la generalidad de las causas; por otra, las especialidades que pudieran establecerse para agilizar los procesos podrían entrar en conflicto con los derechos fundamentales que la propia Constitución reconoce a los sujetos pasivos del proceso penal, en la medida en que estas especialidades llevaran consigo algún sacrificio de las garantías de la defensa.

En realidad, en las causas penales hay que contemplar los derechos fundamentales de las víctimas lesionados por el hecho delictivo, pero también los derechos fundamentales que en todos los países civilizados se reconocen a los sujetos pasivos del proceso (investigados, encausados o acusados).

Ahora bien, quienes tienen que respetar estos últimos derechos fundamentales son las autoridades que intervienen en la justicia penal: la policía, los fiscales y los jueces. Las lesiones a los derechos fundamentales vinculadas a las garantías del proceso penal las cometen estos sujetos y se cometen normalmente en el seno de las actuaciones del proceso penal o preparatorias del proceso. Frente a esta clase de ataques a los derechos fundamentales la tutela jurisdiccional debe producirse dentro del propio proceso penal.

Por un lado, porque los jueces y tribunales penales deben actuar y velar por que la policía y el resto del personal que depende de ellos actúe respetando las garantías procesales, de manera que no se produzcan actuaciones lesivas de los derechos fundamentales de los sujetos pasivos del proceso.

Pero también, porque para el caso de que se produzca en el proceso alguna actuación lesiva de derechos fundamentales del investigado o acusado, el tribunal penal debe aplicar los mecanismos procesales legalmente 
previstos para eliminar la lesión, cuando sea posible, y privar de efectos a la actuación lesiva para que esta no tenga consecuencias perjudiciales para el titular del derecho fundamental atacado.

Entre los mecanismos de tutela de los derechos fundamentales dentro del propio proceso en que se produce el ataque a los mismos se incluye, por ejemplo, la prohibición de fundar el juicio de hecho determinante de la condena en pruebas obtenidas con vulneración de derechos fundamentales, establecida en el art. 11.1 de la Ley Orgánica del Poder Judicial (LOPJ), y también, y muy especialmente, el sistema de recursos, tanto devolutivos como no devolutivos.

Mediante los recursos se puede pedir la revocación de cualquier resolución lesiva de derechos fundamentales al mismo tribunal que la dictó o a un tribunal superior. Los recursos son, por tanto, útiles herramientas de tutela jurisdiccional de los derechos fundamentales.

Precisamente esta vía de los recursos es la que convierte a la Sala de lo Penal del Tribunal Supremo en una instancia decisiva en materia de protección jurisdiccional de los derechos fundamentales de los sujetos pasivos del proceso.

En todo caso, la posibilidad de basar el recurso de casación en infracción de precepto constitucional fue abierta por el art. 5.4 LOPJ (Ley Orgánica 6/1985, de 1 de julio). Este precepto dispone que «en todos los casos en que, según la ley, proceda recurso de casación, será suficiente para fundamentarlo la infracción de precepto constitucional». Esta previsión, a partir de la Ley 1/2000, se incorpora en el art. 852 de la Ley de Enjuiciamiento Criminal (LECrim.). Con base en estos preceptos, cualquier lesión de derechos fundamentales cometida en el desarrollo del proceso penal puede ser sometida mediante el recurso de casación a la Sala de lo Penal del Tribunal Supremo, permitiendo a esta Sala corregir las vulneraciones $\mathrm{y}$, al mismo tiempo, establecer la doctrina jurisprudencial oportuna acerca de la interpretación y aplicación de los derechos fundamentales del sujeto pasivo del proceso penal.

Hasta el año 2015 la tutela de los derechos fundamentales mediante el recurso de casación penal estaba sujeta a un límite: solamente tenían acceso a casación las sentencias dictadas por las audiencias en juicio oral y única instancia. Por tanto, en las causas por delitos castigados con penas de hasta cinco años de privación de libertad, que se resuelven por el Juzgado de lo Penal con segunda instancia ante la Audiencia Provincial, era esta y no el Tribunal Supremo la que decía la última palabra, también en materia de violación de derechos fundamentales. 
Esta limitación ha desaparecido con la reforma de la regulación de la casación penal realizada por la Ley 41/2015, de 5 de octubre. A partir de esta reforma son recurribles en casación las sentencias dictadas en apelación tanto por las Salas de lo Civil y Penal de los Tribunales Superiores de Justicia como por las Audiencias Provinciales. Con ello desaparecen las barreras para el acceso a la casación penal basadas en la gravedad del delito.

Mediante el recurso de casación, por tanto, el Tribunal Supremo desempeña un importante papel en la tutela de los derechos fundamentales, pero esto no significa que este Tribunal diga la última palabra en esta materia. El art. 53.2 de la Constitución es muy claro: la tutela de los derechos y libertades a que se refiere dicho precepto se puede recabar, sí, de los tribunales ordinarios, pero también del Tribunal Constitucional, mediante el recurso de amparo.

¿Cómo se articula esta concurrencia de los tribunales ordinarios y el Tribunal Constitucional en una misma función?

Del art. 53.2 CE cabe deducir que el objeto del recurso de amparo son pretensiones de tutela jurisdiccional frente a violaciones de los derechos y libertades de los arts. 14 a 29.

Sujeto activo de estas pretensiones puede ser, con legitimación propia, cualquier persona «con interés legítimo» [art. 162.1.b) CE], lo que significa que cualquier persona que afirme haber padecido alguna violación de sus derechos y libertades comprendidos en el ámbito del recurso de amparo puede presentar la correspondiente demanda ante el Tribunal Constitucional.

En cuanto al sujeto pasivo de la pretensión, de la Constitución se deduce que puede serlo cualquiera de los «poderes públicos» (lo que incluye, por supuesto, al judicial), puesto que todos ellos están «vinculados» a los derechos y libertades susceptibles de amparo y todos ellos, en consecuencia, pueden violar, con su actuación, esos derechos y libertades (art. 53.1 CE).

Finalmente, por lo que se refiere al contenido de la pretensión, parece evidente que si la Constitución quiere que el Tribunal Constitucional se ocupe de casos concretos de violación de derechos y libertades fundamentales es para que el sujeto que haya padecido la violación pueda obtener del Tribunal una tutela efectiva, lo que significa que la Constitución no excluye, a priori, ningún contenido de la pretensión que sea conducente para lograr esa tutela.

En consonancia con las previsiones constitucionales, la Ley Orgánica del Tribunal Constitucional (LOTC), en su redacción originaria, configu- 
ró el recurso de amparo como un instrumento procesal que permitía plantear ante el Tribunal Constitucional pretensiones dirigidas a restablecer o preservar los derechos y libertades ante violaciones originadas por las disposiciones, actos jurídicos, omisiones o simple vía de hecho de los poderes públicos del Estado, las Comunidades Autónomas y demás entes públicos de carácter territorial, corporativo o institucional, así como de sus funcionarios o agentes.

Entre estos actos de los poderes públicos que pueden ser objeto de un recurso de amparo se encuentran las resoluciones de los órganos jurisdiccionales. El recurso de amparo puede llegar a afectar a resoluciones judiciales por dos vías:

En primer lugar, cuando el amparo se solicita frente a violaciones de derechos fundamentales originadas por actos de las Administraciones Públicas y no reparadas por los tribunales ordinarios. En estos casos el objeto del amparo es el acto del gobierno o de la administración (art. 43 LOTC), pero al haberse enjuiciado ya la presunta violación de derechos fundamentales por los tribunales ordinarios, la decisión del Tribunal Constitucional inevitablemente envolverá, bien confirmación del acierto de la previa decisión desestimatoria del tribunal ordinario, bien una corrección de dicha decisión, en caso de que se estime el amparo.

La segunda vía por la que el recurso de amparo puede afectar a resoluciones judiciales se plantea cuando se pide el amparo frente a violaciones de derechos fundamentales con origen inmediato y directo en un acto u omisión de un órgano judicial (art. 44 LOTC). Esta es la vía por la que normalmente se plantean los recursos de amparo por violación de los derechos fundamentales vinculados a las garantías del proceso penal: la violación de estos derechos se produce en el proceso penal por actos u omisiones del tribunal penal; estas violaciones pueden ser enmendadas dentro del propio proceso a través de los recursos, incluyendo, en último término, el recurso de casación ante la Sala Segunda. Ahora bien, agotados los recursos posibles ante la jurisdicción ordinaria sin que la lesión constitucional haya sido reparada, cabe solicitar la tutela del derecho fundamental mediante el recurso de amparo ante el Tribunal Constitucional. El objeto del recurso de amparo será, en este caso, la resolución judicial que de manera directa e inmediata haya lesionado el derecho fundamental y todas las posteriores que hayan desestimado los recursos planteados contra esta.

En este esquema cabe, por tanto, y no es raro en la práctica que suceda, que las sentencias de la Sala Segunda del Tribunal Supremo que desestiman recursos de casación basados en infracción de precepto constitucio- 
nal por vulneración de derechos fundamentales sean sometidas al Tribunal Constitucional por medio del recurso de amparo, lo que abre la posibilidad de que el Tribunal Constitucional anule y deje sin efecto las sentencias del Tribunal Supremo.

La propia Constitución avala esta posibilidad al disponer su art. 123.1 que el Tribunal Supremo es el órgano jurisdiccional superior en todos los órdenes, salvo lo dispuesto en materia de garantías constitucionales.

Este sistema de tutela de los derechos fundamentales ha funcionado razonablemente bien y ha producido frutos importantes. Voy a referirme rápidamente a algunos que, a mi juicio, ilustran bien la importancia que ha tenido la labor desarrollada tanto por el Tribunal Constitucional como por el Tribunal Supremo en la tutela de los derechos fundamentales relacionados con las garantías del proceso penal.

Muy importante ha sido, por ejemplo, la incidencia que ha tenido en la justicia penal española la jurisprudencia de estos dos tribunales sobre la presunción de inocencia del art. 24.2 de la Constitución. La Sentencia 31/1981, de 28 de julio, sentó los pilares de la doctrina del Tribunal Constitucional sobre la presunción de inocencia y, con ello, inició un proceso de transformación de nuestra justicia penal de enorme magnitud. Esta sentencia no chocaba con las previsiones de la Ley de Enjuiciamiento Criminal. Por el contrario, era plenamente acorde con lo que Alonso Martínez pretendía en 1882. Pero el problema no estaba en esta Ley, sino en la práctica de los tribunales penales que minusvaloraba la necesidad de practicar la prueba en el juicio oral y no vacilaba en fundamentar las condenas en materiales procedentes de la instrucción. La jurisprudencia del Tribunal Constitucional sobre la presunción de inocencia, generada en recursos de amparo por violación de dicho derecho fundamental, fue siendo asumida durante los años ochenta por la Sala Segunda del Tribunal Supremo y, a través de este, por todos los tribunales penales, que fueron aceptando la necesidad de prueba de cargo, practicada en el juicio oral, para fundamentar la condena y la obligada absolución del acusado cuando no existe prueba de tales características, aunque los miembros del tribunal estén subjetivamente convencidos de la culpabilidad del acusado.

También ha tenido mucha importancia, por su poder transformador de la justicia penal española, la doctrina del Tribunal Constitucional sobre el derecho a un proceso con todas las garantías. Este Tribunal ha ido llenando de contenido este derecho tan genérico, incluyendo en él cuestiones clave como la imparcialidad del juzgador y las exigencias del principio acusatorio. 
En cuanto al juez imparcial, es obligada la referencia a la doctrina sobre la incompatibilidad de las funciones de instrucción y enjuiciamiento. Esta doctrina provocó una verdadera revolución de la justicia penal española tras la Sentencia del Tribunal Constitucional (STC) 145/1988. Aunque esta sentencia fue dictada en una cuestión de inconstitucionalidad (contra la Ley Orgánica 10/1980, de 11 de noviembre, de enjuiciamiento oral de delitos dolosos, menos graves y flagrantes), su doctrina se aplicó en recursos de amparo posteriores, hasta que se aprobó la reforma de la LECrim. que aseguraba siempre la separación de las funciones de instrucción y enjuiciamiento (Ley Orgánica 7/1988, de 28 de diciembre).

Respecto al principio acusatorio, la jurisprudencia constitucional ha sido decisiva para la efectiva implantación de sus exigencias en la práctica de los tribunales penales españoles, asentando firmemente la regla de que no es posible la condena de una persona que no ha sido acusada por un sujeto legitimado distinto del tribunal penal.

También cabe mencionar, entre los frutos más importantes de la labor de los Tribunales Constitucional y Supremo en relación con las garantías del proceso penal y los derechos fundamentales que de ellas derivan, la jurisprudencia sobre el secreto de las comunicaciones y la intervención de comunicaciones telefónicas.

En este ámbito, la insuficiente regulación legal del art. 579 LECrim. (reformado por Ley Orgánica 4/1988) había provocado que España fuese condenada por el Tribunal Europeo de Derechos Humanos (TEDH) en el caso Prado Bugallo. Pero en el posterior caso Abdulkadir Coban c. España, de 26 de septiembre de 2006, se evitó la condena, pese a que la regulación legal seguía siendo la misma, precisamente porque el TEDH constata que junto al art. 579 LECrim. existía una sólida doctrina jurisprudencial que suplía las deficiencias de la regulación legal y cumplía las exigencias derivadas del Convenio Europeo de Derechos Humanos (CEDH).

A la vista de estos ejemplos, y de otros muchos que se podrían poner, cabe concluir que el balance es claramente positivo. Pero hay que decir que este balance se ve ensombrecido por una reforma que ha debilitado el recurso de amparo constitucional hasta privarlo prácticamente de una eficacia real como herramienta de tutela de los derechos fundamentales en general y de los vinculados a las garantías procesales penales en particular.

Me refiero a la reforma de la LOTC operada por la Ley Orgánica 6/2007, de 24 de mayo. Esta reforma se produce en el contexto de una situación de grave sobrecarga de trabajo del Tribunal Constitucional motivada por un número incesantemente creciente de recursos de ampa- 
ro interpuestos. Para hacer frente a esta situación se reforma el régimen de admisión del recurso de amparo, haciendo depender la admisibilidad de que el recurso presente una «especial trascendencia constitucional», lo que a su vez depende de que la decisión del Tribunal Constitucional sobre el recurso sea «importante» para «la interpretación de la Constitución, para su aplicación o para su general eficacia, y para la determinación del contenido y alcance de los derechos fundamentales».

Si el propósito de la reforma era desatascar el Tribunal Constitucional, ciertamente lo ha conseguido. Como consecuencia del criterio de admisión más restrictivo, ha disminuido el número de sentencias dictadas en recursos de amparo, que han pasado de más de 300 en 2005 y 2006 a menos de 100 sentencias diez años después; pero ha disminuido también, muy significativamente, el número de recursos de amparo interpuestos (que ha pasado de más de 10.000 en 2008 y 2009 a menos de 7.000 en 2016), lo que seguramente tiene que ver con la percepción de que tras la reforma el recurso de amparo es de escasa utilidad.

Ahora bien, estos «resultados» se han logrado pagando un precio que supone prácticamente la desactivación del recurso de amparo como instrumento de tutela de los derechos fundamentales. A partir de 2007, el Tribunal Constitucional está legalmente autorizado a denegar la tutela frente a reales violaciones de derechos fundamentales simplemente porque la reparación de la lesión por parte de este Tribunal no presenta «especial trascendencia constitucional».

Con esta reforma, como ha puesto de manifiesto el profesor De la Oliva. se produce un cambio sustancial de función del recurso de amparo: deja de tener la finalidad de amparar a sujetos jurídicos perjudicados por la violación de derechos fundamentales y pasa a ser una herramienta al servicio exclusivo de la función de declarar el sentido que el Tribunal Constitucional quiere atribuir a los preceptos constitucionales que reconocen y regulan los derechos fundamentales y las libertades públicas.

Se ha seguido así en la reforma una posición doctrinal, con importantes defensores entre los constitucionalistas, que defendía que el recurso de amparo debía tener una orientación objetiva y no subjetiva. Esta posición descansaba en el prejuicio de que no es función de los Tribunales Constitucionales ocuparse de los derechos de sujetos concretos y de las violaciones de dichos derechos en momentos determinados. Según esta concepción, lo que corresponde a un Tribunal Constitucional es interpretar la norma constitucional estableciendo su sentido, por lo que una vez cumplido este objetivo no tendría sentido reiterar sentencias para la tutela de derechos fun- 
damentales lesionados cuando dichas sentencias no añadieran nada a la interpretación del sentido y alcance del derecho fundamental vulnerado.

El problema de esta concepción doctrinal, y, por tanto, el de la reforma legal que la traslada a la Ley, es que no responde a la configuración del recurso de amparo en la Constitución.

Guste o no, la Constitución ha querido que el Tribunal Constitucional, además de ocuparse, en exclusiva, de enjuiciar la constitucionalidad de las leyes, se ocupe también de los problemas concretos de Ticios, Cayos y Sempronios. Que cuando Ticio, Cayo o Sempronio acudan al Tribunal Constitucional alegando ser víctimas de una actuación de los poderes públicos lesiva de sus derechos y libertades fundamentales y formulando pretensiones de reparación de la lesión padecida, este Tribunal examine la actuación presuntamente lesiva, juzgue si efectivamente lo es y se pronuncie sobre las pretensiones que el demandante de amparo haya formulado, accediendo a ellas o rechazándolas.

Pero de esta configuración constitucional queda muy poco en la regulación legal del recurso de amparo posterior a la reforma de 2007. La conclusión es clara: la reforma de amparo de 2007 es inconstitucional. Que no se haya declarado así ni se vaya a declarar es explicable, habida cuenta de que la reforma fue promovida desde dentro del mismo órgano que tendría que declararla contraria a la Constitución. Pero que no se declare inconstitucional no supone que no lo sea.

Hay también en la reforma una cierta claudicación del Tribunal Constitucional ante la fuerte presión ejercida en los años anteriores desde el Tribunal Supremo. Los magistrados de este último Tribunal, especialmente los de algunas de sus Salas, no parecían aceptar bien la supremacía del Tribunal Constitucional en materia de garantías constitucionales del art. 123.1 CE. Ello dio lugar a manifestaciones de malestar por parte de magistrados del Tribunal Supremo ante casos en que el Tribunal Constitucional, al estimar algún recurso de amparo, anulaba resoluciones del Supremo. Estas manifestaciones fueron a veces muy aparatosas, y en mi opinión siempre impertinentes, además de completamente injustificadas. Pero es muy probable que pudieran hacer mella en el Tribunal Constitucional y tal vez condicionar alguna de sus decisiones. No resulta fácil de explicar, por ejemplo, la decisión de este Tribunal en relación con la aplicación por la Sala Primera de los criterios de admisión de la casación civil aprobados por Acuerdo de la Junta General de 12 de diciembre de 2000 (SSTC 150/2004, de 20 de septiembre, y 164/2004, de 4 de octubre, y AATC 191/2004, de 26 de mayo, y 201/2004, de 27 de mayo). 
Como consecuencia de la reforma de 2007, en la situación actual, la tutela de los derechos fundamentales vinculados a las garantías del proceso penal ha de procurarse apurando las vías procesales disponibles dentro del propio proceso penal. Se ha de confiar, por tanto, prácticamente de manera exclusiva, en los tribunales penales ordinarios, en cuya cúspide se encuentra la Sala Segunda del Tribunal Supremo. Es importante que desde 2015 el acceso al recurso de casación penal por infracción de precepto constitucional no se encuentra a priori condicionado por la gravedad del delito que haya sido objeto del proceso, lo que puede ampliar el alcance de la tutela de los derechos fundamentales por la Sala Segunda del Tribunal Supremo.

Lamentablemente, sin embargo, el recurso de amparo, desde la reforma de 2007, ha quedado prácticamente desprovisto de eficacia real como medio de tutela de los derechos fundamentales procesales. Con ello se debilita la tutela de estos derechos y tampoco favorece al prestigio del Tribunal Constitucional. La única razón por la que muchas veces habrá que interponer un recurso de amparo, aunque se sepa de antemano destinado a la inadmisión por falta de «especial trascendencia constitucional», es la necesidad de agotar los recursos internos para poder presentar demanda ante el TEDH.

A este respecto, hay ya algún trabajo que demuestra que, tras la reforma de 2007, se ha producido un incremento en el número de demandas contra España ante el TEDH y un aumento en el número de sentencias que declaran que España ha vulnerado uno de los derechos del CEDH. Parece ser que, con frecuencia, tales demandas ante Estrasburgo se plantean después de que el Tribunal Constitucional haya inadmitido un recurso de amparo previo por carecer de «especial trascendencia constitucional». No creo que debamos felicitarnos de que esté ocurriendo esto y algo deberíamos hacer para evitarlo. 